\title{
Changes in Rainfall in Sri Lanka during 1966 - 2015
}

\author{
K.L.A.A. Karunathilaka, H.K.V. Dabare and K.D.W. Nandalal
}

\begin{abstract}
The aim of this study was to analyse the annual and seasonal rainfall trends in Sri Lanka during the 50 year period from 1966 to 2015 using rainfall data collected at 32 rain gauging stations. The seasons considered were the two principal monsoon seasons and the two inter-monsoon seasons. Non-parametric Mann-Kendall trend test and Sen's Slope estimator method were used to examine the rainfall trends and determine their magnitudes. According to the analysis which was based on annual rainfall data, 21 of the gauging stations were showing increasing trends. The balance 11 stations were showing decreasing trends. Four of the stations, namely those at Anuradhapura, Batticaloa, Mapakadawewa and Pottuvil had significantly increasing trends. The three stations at Chilaw, Dandeniya Tank and Iranamadu Tank showed significantly decreasing trends. In general, the eastern region of the country has shown over the last half century an increasing rainfall trend and the western, northern and south western regions and the central hills of the country have shown a decreasing rainfall trend during the same period. The seasonal rainfall indicated increasing trends during the First-Inter Monsoon, Second-Inter Monsoon and Northwest Monsoon seasons at a majority of the stations. In contrast, during the Southwest Monsoon season, most of the gauging stations have shown downward rainfall trends.
\end{abstract}

Keywords: Rainfall Trend, Annual and Seasonal Rainfall, Mann-Kendall test, Sen's Slope method

\section{Introduction}

Water plays a major role in agriculture and rainfall has been the primary source of water for agriculture all over the world. Rainfall has also been the primary source for hydropower generation, drinking water supply as well as many industries. In contrast, rainfall also causes disasters such as floods and landslides. Thus, rainfall affects our lives in many ways.

Rainfall has three main characteristics, namely the amount, frequency and intensity, which can vary both spatially and temporally. A good knowledge on the expected amount of rainfall becomes very important when planning and managing water related activities.

The rainfall received in a region may vary with time due to diverse physical and anthropological factors such as ozone depletion, global warming, deforestation, fossil fuel burning, industrial gas emissions etc. The investigation of changes in the rainfall in the recent past which will help to ascertain their trends, is vital when planning water management practices for the future. This paper presents an investigation made towards understanding the rainfall trends in Sri Lanka during the last 50 year period.

Rainfall trends in Sri Lanka in the 100 years leading upto 1998 have been studied based on the monthly rainfall data recorded at 15 gauging stations [1]. In this study, Mann-
Kendall statistic, Spearman statistic and leastsquare regression method have been chosen to detect the trends in the rainfall time series. In order to identify the trends, the data sets have been divided into two time periods, i.e., as a long-range study (98 to 130 years) and a shortrange study (36 to 50 years). A long-term increasing trend at a 95\% confidence level had been observed in Colombo at a rate of 3.15 $\mathrm{mm} /$ year. Decreasing long-term trends had been found at two locations, i.e., at NuwaraEliya at a rate of $4.87 \mathrm{~mm} / \mathrm{yr}$ and at Kandy at a rate of $2.88 \mathrm{~mm} / \mathrm{yr}$. However, more recent data records (1949 onwards), have revealed a decreasing trend at 13 out of the 15 stations. In general, the downward trends in the recent decades were steeper than the long term variations. In the recent data records, the largest downward trend of $11.16 \mathrm{~mm} / \mathrm{yr}$ has been observed at Batticaloa.

In another study, the change in the climate of Sri Lanka based on rainfall characteristics has been studied using daily rainfall data collected at 22 gauging stations during the period from

Mr.K.L.A.A.Karunathilaka, Student Member of IESL, B.Sc. Eng. (Hons), Sanken Construction (Pvt) Ltd., Colombo. Email:ach.ayodhya@gmail.com

Mr.H.K.V.Dabare, Student Member of IESL, B.Sc. Eng. (Hons), Vonlan Construction (Pvt) Ltd., Polonnaruwa. Email:hkvdabare91@gmail.com

Eng.(Prof.)K.D.W.Nandalal, Int.PEng.(SL), C.Eng., FIE(Sri Lanka), B.Sc. Eng. (Hons), MEng(AIT), Ph.D.(The Netherlands), Senior Professor, Department of Civil Engineering, University of Peradeniya. Email:kdwn@pdn.ac.lk 
1961 to 2002 [2]. This study investigated spatial and temporal trends in the rainfall received over the period from 1961 to 2002 during the four seasons, i.e., Southwest Monsoon, Firstinter Monsoon, Northeast Monsoon and Second-inter Monsoon. According to the results, the number of rainy days has decreased at all of the stations except at the NuwaraEliya station. At all other 21 stations except at the one at Jaffna, the annual rainfall has decreased. The study further reports that the $2000 \mathrm{~mm}$ isohyet that demarcates the wet zone of the country has shrunk.

Rainfall trends in Sri Lanka during the 130 years since 1870 and their relationships to El Nino-southern oscillation have also been studied [3]. In this study, the fluctuations in the precipitation associated with the four seasons have been analysed at 15 locations in Sri Lanka. The study presented in detail the changes in rainfall at the 15 locations during different seasons.

This paper presents the rainfall trends observed in Sri Lanka in the recent past, both spatially and temporally, based on the rainfall records maintained at 32 gauging stations.

\section{Methodology}

Rainfall data gathered for the study were screened to investigate their accuracy before using them in the analysis. In order to determine the rainfall trends, the non parametric Mann-Kendall test was performed followed by Sen's slope estimation method. That is, the statistical significance trend detected using Mann-Kendall test was complemented with Sen's slope estimation to determine the magnitude of the trend. Finally, the spatial rainfall trends in Sri Lanka, both annually and seasonally are presented.The four seasons are; First-Inter Monsoon (March April), Southwest Monsoon (May - September), Second-Inter Monsoon (October - November) and Northeast Monsoon (December February).

\subsection{Data}

Monthly rainfall data recorded at 32 rainfall gauging stations over the last half century (1966 - 2015) were used for the study. The stations which were selected to cover the country uniformly as much as possible are shown in
Figure 1. The bulk of the data were gathered from the Department of Meteorology, Sri Lanka. Some data were collected from the data published by Nakagawa et al [4] in 1995.

\subsection{Data Screening}

Data screening is done to assure the quality of data before their use in a study. The procedure starts with a rough screening of the data. Thereafter, it is checked whether there is any trend in the data. The stability of the variance and the mean are thereafter examined. Finally, the data is tested for any absence of persistence.

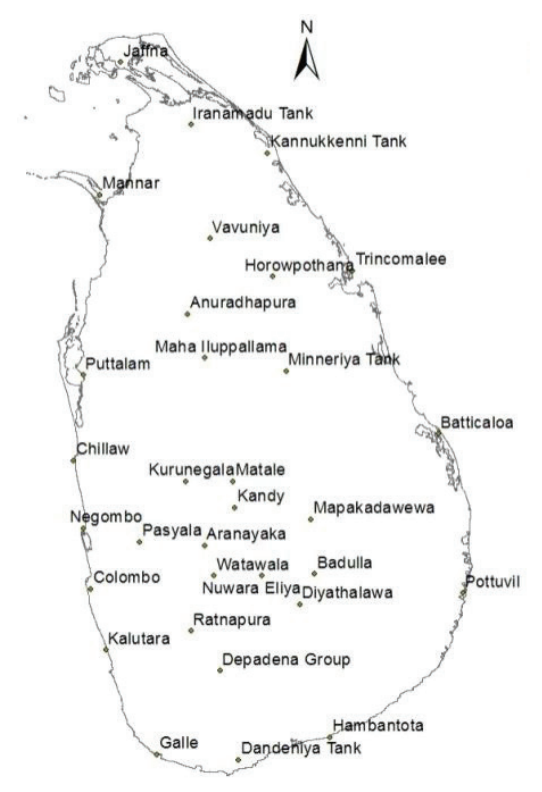

Figure 1 - Locations of rainfall gauge stations

The initial rough screening is done through visual detection. It will identify whether the observations have been consistently or accidentally credited to the wrong day, whether they show gross errors (e.g., weekly readings instead of daily readings) or whether they contain misplaced decimal points. Spearman's Rank-Correlation Method is used to see whether there is a trend in the data series. The stability of variance is tested using the F-Test and the stability of the mean is tested using the t-Test. These assure stationarity of the data series. Finally, the absence of persistence is tested by estimating the serial correlation coefficient. If these tests are successful, the data will be considered as suitable for use in the rainfall analysis.

\subsection{Mann-Kendall Method}

The Mann-Kendall test $[5,6]$ has been widely used to detect trends in meteorological, 
hydrological and agro-meteorological time series. It is a non-parametric test from which the significance of the detected trend can be obtained at different levels of significance (generally taken as 5\%). Mann-Kendall test is robust to the influence of extremes, performs well with skewed variables and can handle missing values [7]. This method has been widely used in rainfall trend detection studies $[8,9,10]$ and has produced reliable results. The purpose of this test is to determine whether the value of a random variable is generally increasing or decreasing in statistical terms over a certain period of time. This test does not require the assumption of normality of the random variable and will indicate only the direction and not the magnitude of the trends. Trends detectable by the Mann-Kendall method are not necessarily linear. Moreover, the MannKendall test is less affected by the presence of outliers because its test statistic is based on the sign of differences and not directly on the values of the random variable.

The Mann-Kendall test statistic $S$ is estimated $[11,12]$ using Equation (1) given below.

$$
S=\sum_{i=1}^{n-1} \sum_{j=i+1}^{n} \operatorname{sgn}\left(R_{i}-R_{j}\right)
$$

where $R_{i}$ and $R_{j}$ are the annual values in the years $i$ and $j$ respectively with $i>j$, as in Equation (2).

$$
\operatorname{sgn}\left(R_{i}-R_{j}\right)= \begin{cases}+1 & \text { if } R_{i}>R_{j} \\ 0 & \text { if } R_{i}=R_{j} \\ -1 & \text { if } R_{i}<R_{j}\end{cases}
$$

Generally, if a dataset displays a consistently increasing or decreasing trend, $S$ will be positive or negative respectively, with a larger magnitude indicating that the trend is more consistent in the particular direction.

The Variance of the Mann-Kendall statistic is calculated using Equation (3) given below.

$$
\operatorname{var}(S)=\frac{1}{18}[n(n-1)(2 n+5)]
$$

If tie is present in the data then the variance of $S$ would be given by Equation (4) as follows:

$$
\begin{aligned}
\operatorname{var}(S)=\frac{1}{18}[n(n-1)(2 n+5) & \\
& \left.\quad-\sum_{p-1}^{q} t_{p}\left(t_{p}-1\right)\left(2 t_{p}+5\right)\right] \ldots
\end{aligned}
$$

where $n$ is the number of data points, $q$ is the number of tied groups and $t_{p}$ is the number of data values in the $p^{\text {th }}$ group. The test statistic $Z$ is calculated using Equation (5) given below.

$$
Z=\left\{\begin{array}{l}
\frac{S-1}{\sqrt{\operatorname{var}(S)}} \text { if } S>0 \\
0 \quad \text { if } S=0 \\
\frac{S+1}{\sqrt{\operatorname{var}(S)}} \text { if } S<0
\end{array}\right.
$$

The hypothesis of no trend would be rejected if

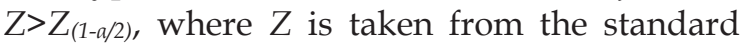
normal distribution table and $a$ is the level of significance. This means that there would be a probability a that a trend is falsely identified. By introducing the expected variance of $S$ in determining $\mathrm{Z}$, the Mann-Kendall test is able to reject what might appear to be trends over small periods of time that may be exhibiting short trends. In hypothesis testing, the significance level is the criterion used for rejecting the null hypothesis. Experimenters have used either the 0.05 level (sometimes called the $5 \%$ level) or the 0.01 level ( $1 \%$ level), although the choice of levels is largely subjective. The lower the significance level, the more the data must diverge from the null hypothesis if they are to be considered as significant. In the present study of rainfall variability analysis, 0.05 level was used as it is more conservative than the 0.01 level.

$Z_{(1-a / 2)}$ statistic was calculated as 1.96 using the normal probability distribution table. When $\mathrm{Z}_{1}$ $\alpha / 2>1.96$, the rainfall will have a significantly increasing trend while when $\mathrm{Z}_{1-\alpha / 2}<-1.96$, the rainfall will have a significantly decreasing trend.

\subsection{Sen's Slope Method}

Sen's Slope method $[5,6,12]$ is a nonparametric, linear slope estimator. Unlike linear regression, it is not greatly affected by gross data errors, outliers, or missing data. The Sen's Slope technique is used to determine the magnitude of the trend line. The approach involves computing slopes for all the pairs of ordinal time points using the median of these slopes as an estimate of the overall slope. The 
method proceeds by calculating the slope as a change in measurement per change in time [12] as given in Equation (6) below.

$$
Q=\frac{R_{i}-R_{i}^{\prime}}{i-i^{\prime}} \cdots
$$

where $Q$ is the slope between data points $R_{i}^{\prime}$ and $R_{i}$; are the data measurements at time $i^{\prime}$ and $i$, respectively. The time $i^{\prime}$ comes after time $i$.

The variance for Sen's slope is determined by Equation(7);

$$
\begin{aligned}
& \operatorname{var}(S)=\frac{1}{18}[n(n-1)(2 n+5) \\
& \left.-\sum_{p-1}^{q} t_{p}\left(t_{p}-1\right)\left(2 t_{p}+5\right)\right] \ldots
\end{aligned}
$$

If there are $n$ values $x_{j}$ in the time series, $N=$ $n(n-1) / 2$, the number of slope estimates could be obtained. The $N$ values of $Q_{i}$ are ranked from the smallest to the largest and the median of these $N$ is the Sen's slope as given in Equation. (8).

$$
\begin{array}{ll}
Q^{\prime}=\left(Q_{\frac{n+1}{2}}\right) & \text { if nodd } \\
Q^{\prime}=\frac{1}{2}\left(Q_{\frac{n}{2}}+Q_{\frac{n+2}{2}}\right) & \text { if neven }
\end{array}
$$

where $N$ is the number of calculated slopes.

To estimate the range of ranks for the specified confidence interval of ranks, Equation (9) given below is used.

$$
C_{\alpha}=Z_{1-\alpha / 2} \times \sqrt{\operatorname{var}(S)}
$$

The ranks of the lower $\left(M_{1}\right)$ and upper $\left(M_{2}\right)$ confidence limits are given by Equation (10).

$$
\begin{aligned}
& M_{1}=\frac{N-C_{a}}{2} \\
& M_{2}=\frac{N+C_{a}}{2}
\end{aligned}
$$

After calculating the slopes corresponding to $M_{1}$ and $M_{2}$ as the lower and upper confidence limits respectively, the median slope is defined as being statistically different from zero (for the selected confidence interval), if the zero does not lie between the upper and lower confidence limits. When the hypothesis of no trend is rejected by the Mann-Kendall test (positive value of test statistic indicates an upward trend and a negative value indicates a downward trend), the Sen's Slope is used to quantify the trend.

\section{Results and Discussion}

Initially, screening of data was carried out. Then the Mann-Kendall test was performed to identify the trends of rainfall records and then the Sen's slope method was used to estimate the magnitude of the trend. These were carried out for both annual data and seasonal data.

\subsection{Screening of Data}

A few stations had rainfall gaps. Those were filled using standard methods such as Arithmetic Mean method, Normal Ratio method, Inverse Distance Weighting method, and Linear Regression methodas appropriate. Thereafter, the data were screened using the methods already described. Except the stations at Anuradhapura, Mapakadawewa and Pottuvil , all the other gauging stations satisfied all the tests and the three stations showed high trends. Since this could also be possible, the rainfall data at these three stations were also used for the study.

\subsection{Identification of Trends based on the Mann-Kendall Test}

The rainfall trends at all of the gauging stations were calculated for both annual and seasonal rainfall data. Initially, the trends of annual rainfall values were identified using the MannKendall test. Theraefter, the total seasonal rainfalls during the four seasons were calculated.

Tables 1 and 2 show the results obtained from the annual and seasonal data analysis. As indicated in these Tables, the test indicates whether the trend is only increasing or whether it is only decreasing. Furthermore, it also states whether the trend is significant or not.

Table 1 shows that the rainfalls at 21 stations have an increasing trend while at four of these stations this increasing trend is significant. The stations which show a significantly increasing trend are those at Anuradhapura, Batticaloa, Mapakadawewa and Pottuvil. Altogether, 11 stations show decreasing rainfall trends. Out of them, the three stations at Chilaw, Dandeniya tank and Iranamadu tank show significantly 
decreasing trends. In general, on an annual scale, the eastern region of the country has shown an increasing trend while the western region has shown a decrease of the rainfall over the period of analysis.

As Table 2 indicates, during the First-Inter Monsoon season, the rainfalls at 21 stations show increasing trends while at 4 of them the trend is significant. These four stations are at Anuradhapura, Jaffna, Mapakadawewa and Matale. Out of the other 11 stations that show decreasing trends during that season, only the station at Chilaw shows a significantly decreasing trend. During the Southwest Monsoon season, only seven of the stations show an increasing trend. Interestingly, no station shows a significant upward trend. Out of the 25 stations showing decreasing trends, three have significant trends. They are the stations at Chilaw, Horowpothana and Kurunegala. Altogether, 22 stations show increasing rainfall trends during the SecondInter Monsoon season. Two stations among them have significant increases. During that season, no station shows a significant decrease in the rainfall. Finally, during the Northeast Monsoon season, 27 stations show increasing trends in the rainfall while 5 of the stations show significant increases. These stations are located at Anuradhapura, Batticaloa, Horowpothana, Kandy and Mapakadawewa. Only 5 stations have decreasing rainfall trends during the season.

These observations suggest a decrease in rainfall during the Southwest Monsoon period while there is an increase in the rainfall during the Northeast Monsoon season. An increase in the rainfall trends is observed during the two inter monsoon seasons at a majority of the stations.

\subsection{Estimation of the Trend based on Sen's Slope Method}

The Sen's Slope Method was employed to calculate the magnitude of the slope of the rainfall trend as rainfall changes over a year. Trends were calculated for both annual totals and seasonal totals at all 32 gauging stations. Results are presented in Tables 1 and 2 for the annual and seasonal trends respectively.

The increasing rainfall trends at the stations at Anuradhapura, Batticaloa, Mapakadawewa and Pottuvil identified based on the annual data are $6.31 \mathrm{~mm} / \mathrm{yr}, 9.77 \mathrm{~mm} / \mathrm{yr}, 16.25 \mathrm{~mm} / \mathrm{yr}$ and
$19.89 \mathrm{~mm} / \mathrm{yr}$ respectively. Mapakadawewa and Pottuvil rainfalls have increased considerably over the past 50 year period. The increase in the annual rainfall and the decrease in the number of rainy days [2\} suggest intense rains at these stations. The significantly decreasing rainfall trends at the stations at Chilaw, Dandeniya Tank and Iranamadu Tank are 7.87 $\mathrm{mm} / \mathrm{yr}, 8.73 \mathrm{~mm} / \mathrm{yr}$ and $6.58 \mathrm{~mm} / \mathrm{yr}$ respectively. The increasing trends are higher than the decreasing trends.

Table 1 - Trend of annual rainfall at the 32 gauge stations

\begin{tabular}{|r|l|c|c|c|}
\multirow{2}{*}{ No. } & \multirow{2}{*}{ Station } & \multicolumn{2}{|c|}{ Mann-Kendall } & Sen's Slope \\
\cline { 2 - 5 } & & Trend & Z Statistic & Slope (mm/yr.) \\
\hline 1 & Anuradhapura & $\uparrow \uparrow$ & 2.70 & 6.31 \\
\hline 2 & Aranayaka & $\downarrow$ & -1.20 & -8.05 \\
\hline 3 & Badulla & $\uparrow$ & 1.61 & 5.91 \\
\hline 4 & Batticaloa & $\uparrow \uparrow$ & 2.43 & 9.77 \\
\hline 5 & Chillaw & $\downarrow \downarrow$ & -2.21 & -7.87 \\
\hline 6 & Colombo & $\uparrow$ & 0.18 & 0.66 \\
\hline 7 & Dandeniya Tank & $\downarrow \downarrow$ & -2.02 & -8.73 \\
\hline 8 & Deepadena Group & $\uparrow$ & 0.33 & 1.37 \\
\hline 9 & Diyathalawa & $\uparrow$ & 1.06 & 2.99 \\
\hline 10 & Galle & $\uparrow$ & 0.32 & 1.34 \\
\hline 11 & Hambantota & $\uparrow$ & 0.53 & 1.48 \\
\hline 12 & Horowpothana & $\uparrow$ & 1.38 & 3.94 \\
\hline 13 & Iranamadu Tank & $\downarrow \downarrow$ & -2.24 & -6.58 \\
\hline 14 & Jaffna & $\uparrow$ & 0.94 & 3.54 \\
\hline 15 & Kalutara PWD & $\downarrow$ & -0.86 & -3.21 \\
\hline 16 & Kandy & $\uparrow$ & 0.74 & 2.21 \\
\hline 17 & Kannukkenni Tank & $\downarrow$ & -1.16 & -5.74 \\
\hline 18 & Kurunegala & $\downarrow$ & -1.12 & -4.61 \\
\hline 19 & Maha lluppallama & $\uparrow$ & 0.69 & 1.75 \\
\hline 20 & Mannar & $\uparrow$ & 1.20 & 1.77 \\
\hline 21 & Mapakadawewa & $\uparrow \uparrow$ & 3.92 & 16.25 \\
\hline 22 & Matale PWD & $\uparrow$ & 1.17 & 5.17 \\
\hline 23 & Minneriya Tank & $\uparrow$ & 0.38 & 1.25 \\
\hline 24 & Negombo & $\downarrow$ & -0.20 & -1.03 \\
\hline 25 & Nuwara Eliya & $\downarrow$ & -0.80 & -2.35 \\
\hline 26 & Pasyala & $\downarrow$ & -0.07 & -0.49 \\
\hline 27 & Pottuvil & $\uparrow \uparrow$ & 3.21 & 19.89 \\
\hline 28 & Puttalam & $\uparrow$ & 0.47 & 1.35 \\
\hline 29 & Ratnapura & $\uparrow$ & 0.20 & 0.92 \\
\hline 30 & Trincomalee & $\uparrow$ & 1.73 & 5.97 \\
\hline 31 & Vavuniya & $\uparrow$ & 0.46 & 1.87 \\
\hline 32 & Watawala & -0.49 & -4.97 \\
\hline & & & \\
\hline & & $\downarrow$ & & \\
\hline
\end{tabular}

$\uparrow$ - Upward Trend, $\quad \uparrow \uparrow$ - Significantly Upward Trend

$\downarrow$ - Downward Trend, $\downarrow \downarrow$ - Significantly Downward Trend

Though a significantly increasing trend of 3.15 $\mathrm{mm} / \mathrm{yr}$ was estimated for Colombo based on the data of a 130 year period leading upto 1998 [1], the present study shows that the increasing trend has only been $0.66 \mathrm{~mm} / \mathrm{yr}$ over the last 50 year period from 1966 to 2015. Jayawardena et al [1] found Kandy to have negative trends based on 130 year long and 50 year long rainfall data records leading upto 1998. However, the present study shows that there has been an upward trend of rainfall at Kandy during the past 50 years leading upto 2015. In addition, the station at NuwaraEliya showed a decreasing trend of $5.31 \mathrm{~mm} / \mathrm{yr}$ based on data collected 
upto 1998 [1] while for the period 1966-2015, the decreasing trend is $2.35 \mathrm{~mm} / \mathrm{yr}$. That is, the rate of decrease has reduced. These observations suggest an increase in the rainfalls at these stations.

Figure 2 depicts graphically the trend rates for the annual data. As it clearly shows, the eastern region of the country has had an increasing trend over the last half century while the western, northern and southern regions and the central hills of the country have had decreasing rainfall trends. It is noticed that the majority of the country shows an increasing trend of rainfall.

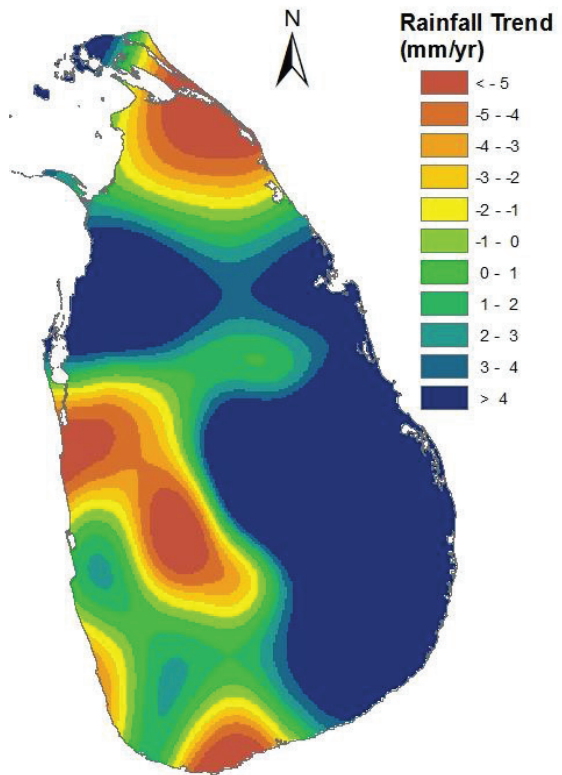

Figure 2 - Spatial distribution of annual rainfall trend

Table 2 -Trend of seasonal rainfall at the 32 gauge stations

\begin{tabular}{|c|c|c|c|c|c|c|c|c|c|c|c|c|c|}
\hline \multirow{3}{*}{ No. } & \multirow{3}{*}{ Station } & \multicolumn{3}{|c|}{ First Inter-Monsoon } & \multicolumn{3}{|c|}{ Southwest Monsoon } & \multicolumn{3}{|c|}{ Second Inter-Monsoon } & \multicolumn{3}{|c|}{ Northeast Monsoon } \\
\hline & & \multicolumn{2}{|c|}{ Mann-Kendall } & \multirow{2}{*}{\begin{tabular}{|c|} 
Sen's \\
Slope \\
$(\mathrm{mm} / \mathrm{yr})$ \\
\end{tabular}} & \multicolumn{2}{|c|}{ Mann-Kendall } & \multirow{2}{*}{$\begin{array}{c}\text { Sen's } \\
\text { Slope } \\
(\mathrm{mm} / \mathrm{yr})\end{array}$} & \multicolumn{2}{|c|}{ Mann-Kendall } & \multirow{2}{*}{$\begin{array}{c}\text { Sen's } \\
\text { Slope } \\
(\mathrm{mm} / \mathrm{yr} .\end{array}$} & \multicolumn{2}{|c|}{ Mann-Kendall } & \multirow{2}{*}{$\begin{array}{c}\text { Sen's } \\
\begin{array}{c}\text { Slope } \\
(\mathrm{mm} / \mathrm{yr}\end{array}\end{array}$} \\
\hline & & Trend & Z Statistic & & Trend & Z Statistic & & Trend & Z Statistic & & Trend & Z Statistic & \\
\hline 1 & Anuradhapura & $\uparrow \uparrow$ & 2.87 & 2.77 & $\downarrow$ & -0.90 & -1.18 & $\uparrow$ & 1.62 & 2.71 & $\uparrow \uparrow$ & 2.43 & 4.39 \\
\hline 2 & Aranayaka & $\uparrow$ & 0.02 & 0.04 & $\downarrow$ & -1.72 & -6.51 & $\downarrow$ & -0.07 & -0.33 & $\uparrow$ & 0.85 & 1.47 \\
\hline 3 & Badulla & $\uparrow$ & 0.78 & 0.98 & $\downarrow$ & -0.17 & -0.16 & $\uparrow$ & 1.82 & 3.01 & $\uparrow$ & 1.47 & 2.44 \\
\hline 4 & Batticaloa & $\downarrow$ & -0.28 & -0.30 & $\downarrow$ & -0.48 & -0.37 & $\uparrow$ & 1.01 & 2.19 & $\uparrow \uparrow$ & 2.17 & 7.50 \\
\hline 5 & Chillaw & $\downarrow \downarrow$ & -2.52 & -3.27 & $\downarrow \downarrow$ & -2.83 & -4.50 & $\downarrow$ & -0.60 & -1.38 & $\downarrow$ & -0.49 & -0.45 \\
\hline 6 & Colombo & $\uparrow$ & 1.03 & 1.75 & $\downarrow$ & -0.94 & -2.04 & $\uparrow$ & 0.01 & 0.03 & $\uparrow$ & 1.10 & 1.62 \\
\hline 7 & Dandeniya Tank & $\downarrow$ & -0.86 & -0.87 & $\downarrow$ & -1.25 & -4.50 & $\downarrow$ & -0.70 & -1.29 & $\downarrow$ & -0.77 & -0.98 \\
\hline 8 & Deepadena Group & $\uparrow$ & 1.03 & 1.79 & $\downarrow$ & -1.45 & -5.37 & $\uparrow$ & 0.20 & 0.71 & $\uparrow$ & 1.80 & 3.54 \\
\hline 9 & Diyathalawa & $\uparrow$ & 0.57 & 0.50 & $\downarrow$ & -0.76 & -0.77 & $\uparrow$ & 0.15 & 0.11 & $\uparrow$ & 0.44 & 0.61 \\
\hline 10 & Galle & $\uparrow$ & 0.61 & 1.13 & $\uparrow$ & 0.05 & 0.25 & $\uparrow$ & 0.49 & 0.68 & $\uparrow$ & 0.14 & 0.23 \\
\hline 11 & Hambantota & $\downarrow$ & -0.26 & -0.32 & $\downarrow$ & -0.25 & -0.26 & $\uparrow$ & 0.49 & 0.48 & $\uparrow$ & 1.45 & 1.50 \\
\hline 12 & Horowpothana & $\uparrow$ & 1.30 & 1.13 & $\downarrow \downarrow$ & -3.45 & -5.33 & $\uparrow$ & 1.25 & 1.72 & $\uparrow \uparrow$ & 2.91 & 5.20 \\
\hline 13 & Iranamadu Tank & $\downarrow$ & -0.92 & -0.75 & $\downarrow$ & -0.81 & -1.26 & $\downarrow$ & -1.20 & -2.89 & $\uparrow$ & 0.38 & 1.01 \\
\hline 14 & Jaffna & $\uparrow \uparrow$ & 2.27 & 1.52 & $\uparrow$ & 0.21 & 0.38 & $\uparrow$ & 0.54 & 1.51 & $\downarrow$ & -0.27 & -0.50 \\
\hline 15 & Kalutara PWD & $\downarrow$ & -0.28 & -0.49 & $\uparrow$ & 0.22 & 0.49 & $\downarrow$ & -0.64 & -1.31 & $\downarrow$ & -0.03 & -0.05 \\
\hline 16 & Kandy & $\uparrow$ & 0.99 & 0.73 & $\downarrow$ & -1.61 & -3.62 & $\uparrow$ & 0.12 & 0.22 & $\uparrow \uparrow$ & 2.11 & 3.08 \\
\hline 17 & Kannukkenni Tank & $\downarrow$ & -0.28 & 0.00 & $\downarrow$ & -1.61 & -2.18 & $\downarrow$ & -0.18 & -0.52 & $\downarrow$ & -0.28 & -0.95 \\
\hline 18 & Kurunegala & $\uparrow$ & 0.04 & 0.07 & $\downarrow \downarrow$ & -2.04 & -4.18 & $\downarrow$ & -0.95 & -1.77 & $\uparrow$ & 0.99 & 1.27 \\
\hline 19 & Maha Iluppallama & $\uparrow$ & 0.61 & 0.46 & $\downarrow$ & -0.91 & -1.29 & $\uparrow$ & 0.44 & 0.61 & $\uparrow$ & 1.02 & 1.63 \\
\hline 20 & Mannar & $\uparrow$ & 0.04 & 0.04 & $\uparrow$ & 0.60 & 0.43 & $\uparrow$ & 0.42 & 0.72 & $\uparrow$ & 0.45 & 0.50 \\
\hline 21 & Mapakadawewa & $\uparrow \uparrow$ & 2.32 & 2.85 & $\uparrow$ & 1.08 & 1.17 & $\uparrow \uparrow$ & 2.64 & 5.41 & $\uparrow \uparrow$ & 2.59 & 8.44 \\
\hline 22 & Matale PWD & $\uparrow \uparrow$ & 2.04 & 2.58 & $\downarrow$ & -0.26 & -0.34 & $\uparrow$ & 0.32 & 0.71 & $\uparrow$ & 1.34 & 3.41 \\
\hline 23 & Minneriya Tank & $\downarrow$ & -0.50 & -0.40 & $\downarrow$ & -1.15 & -1.58 & $\uparrow$ & 0.03 & 0.10 & $\uparrow$ & 1.59 & 3.56 \\
\hline 24 & Negombo & $\downarrow$ & -0.46 & -1.08 & $\downarrow$ & -1.64 & -3.35 & $\downarrow$ & -0.15 & -0.45 & $\uparrow$ & 1.53 & 2.10 \\
\hline 25 & Nuwara Eliya & $\uparrow$ & 0.49 & 0.36 & $\downarrow$ & -1.50 & -4.75 & $\uparrow$ & 0.40 & 0.44 & $\uparrow$ & 1.24 & 2.01 \\
\hline 26 & Pasyala & $\downarrow$ & -0.01 & -0.13 & $\downarrow$ & -0.36 & -1.28 & $\uparrow$ & 0.38 & 1.03 & $\uparrow$ & 0.14 & 0.43 \\
\hline 27 & Pottuvil & $\downarrow$ & -1.10 & -2.52 & $\uparrow$ & 1.12 & 1.44 & $\uparrow \uparrow$ & 1.98 & 6.70 & $\uparrow$ & 1.91 & 7.61 \\
\hline 28 & Puttalam & $\uparrow$ & 0.24 & 0.28 & $\downarrow$ & -0.05 & -0.06 & $\uparrow$ & 0.17 & 0.21 & $\uparrow$ & 0.94 & 1.15 \\
\hline 29 & Ratnapura & $\uparrow$ & 1.32 & 1.90 & $\downarrow$ & -0.79 & -3.16 & $\uparrow$ & 0.77 & 1.75 & $\uparrow$ & 0.65 & 1.05 \\
\hline 30 & Trincomalee & $\uparrow$ & 0.11 & 0.09 & $\uparrow$ & 0.05 & 0.12 & $\uparrow$ & 1.13 & 2.55 & $\uparrow$ & 1.62 & 3.79 \\
\hline \begin{tabular}{|l|}
31 \\
\end{tabular} & Vavuniya & $\uparrow$ & 0.76 & 0.58 & $\downarrow$ & -1.31 & -2.02 & $\downarrow$ & -0.12 & -0.21 & $\uparrow$ & 1.49 & 3.66 \\
\hline 32 & Watawala & $\uparrow$ & 0.66 & 1.39 & $\downarrow$ & -1.36 & -10.61 & $\downarrow$ & -0.23 & -0.61 & $\uparrow$ & 1.24 & 2.19 \\
\hline
\end{tabular}




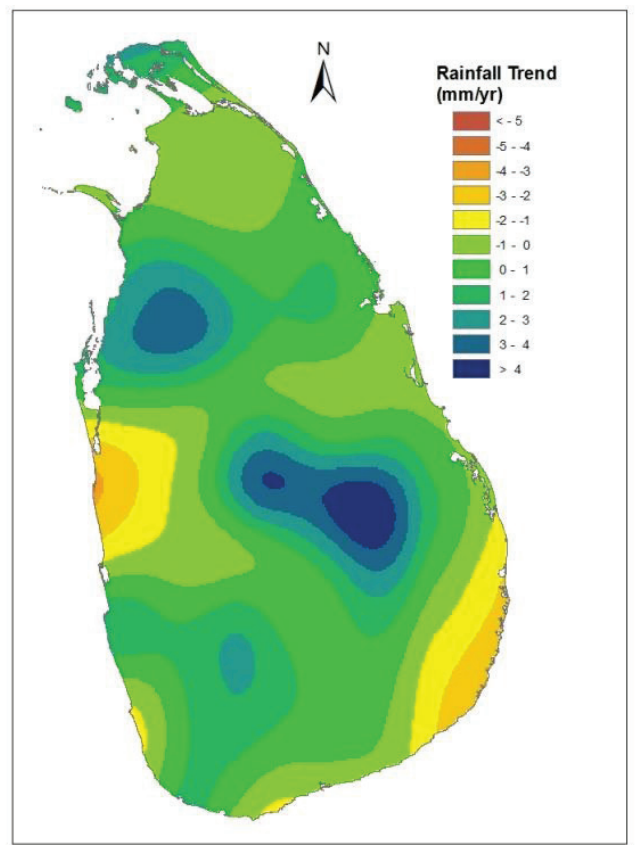

(a) First-Inter Monsoon

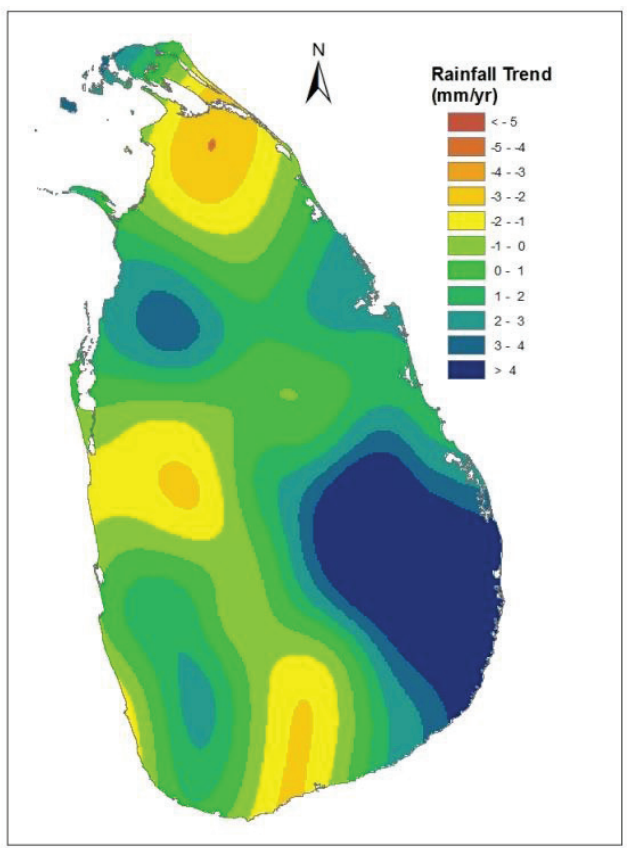

(c) Second-Inter Monsoon

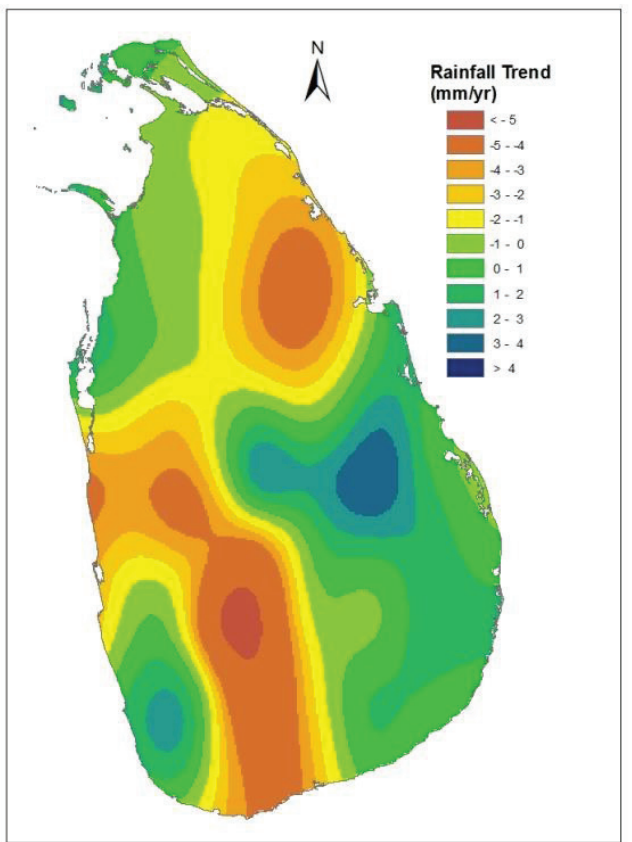

(b) Southwest Monsoon

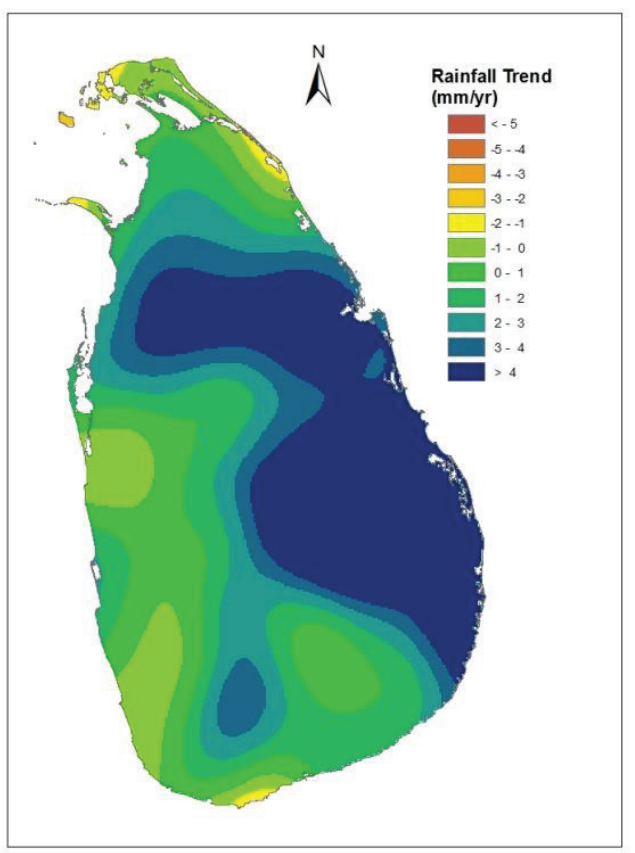

(d) Northeast Monsoon

Figure 3 - Spatial distribution of seasonal rainfall trends

Table 2 shows that in the First-inter Monsoon season, significantly increasing trends at the stations at Anuradhapura $(2.77 \mathrm{~mm} / \mathrm{yr})$, Jaffna (1.52 mm/yr), Mapakadawewa $(2.85 \mathrm{~mm} / \mathrm{yr})$ and Matale $(2.58 \mathrm{~mm} / \mathrm{yr})$ are not very high. The decreasing trend of $3.27 \mathrm{~mm} / \mathrm{yr}$ at Chilaw is moderate.

Significantly decreasing rainfall trends are observed only during the Southwest Monsoon 
season. That is also at 3 of the stations only. These stations are at Chilaw, Kurunegala and Horowpothana and their decreasing rates are $4.50 \mathrm{~mm} / \mathrm{yr}, \quad 5.33 \mathrm{~mm} / \mathrm{yr}$ and $4.18 \mathrm{~mm} / \mathrm{yr}$ respectively. These slopes or rates are moderately high.

Two stations have significantly increasing rainfall trends during the Second-Inter Monsoon season and they are at Mapakadawewa $(5.41 \mathrm{~mm} / \mathrm{yr})$ and Pottuvil $(6.70 \mathrm{~mm} / \mathrm{yr})$. Thus, the rates of increase during this season are high.

During the Northeast Monsoon season, five of the stations have significant upward trends. They are the stations at Anuradhapura with $4.39 \mathrm{~mm} / \mathrm{yr}$, Batticaloa with $7.50 \mathrm{~mm} / \mathrm{yr}$, Mapakadawewa with $8.44 \mathrm{~mm} / \mathrm{yr}$, Kandy with $3.08 \mathrm{~mm} / \mathrm{yr}$ and Horowpothana with $5.20 \mathrm{~mm} / \mathrm{yr}$. The rates of increase are observed to be high during the Northeast Monsoon season.

The analysis indicates that many parts of the country have experienced an increase in the rainfall during the First-Inter monsoon, SecondInter monsoon and Northeast monsoon seasons. In contrast, during the Southwest monsoon, the rainfall trend has reduced throughout the country.

Rainfall trends of seasonal rainfall data are shown in Figure 3. Figure 3(a) shows the trend (slope) variation during the First-Inter Monsoonseason(March-April) over the period of analysis. Usually, convective type thunderstorms occur during this period. As Figure 3(a) shows, increasing rainfall trends are observed in the north-east and north-central regions and in the eastern parts of the central hill country. Western and south-eastern coastal regions have decreasing rainfall trends. However, most of the parts of the country have an increasing trend.

Figure 3(b) shows the rainfall trend variation during the Southwest Monsoon season (MaySeptember). Only south-eastern, eastern and south-western coastal regions have an increasing trend of rainfall though these trends are considerably low. The majority of the country has a decreasing rainfall trend during the season. Western, north-eastern and southern regions along with the western side of the central hills have a significantly decreasing trend of rainfall compared to the other parts of the country.

Rainfall trends during the Second-Inter Monsoon season (October-November) are presented in Figure 3(c). Small areas of the northern, western and southern parts of the country have a decreasing trend of rainfall while all the other parts of the country have had an increase in the rainfall during the period of analysis. North-eastern, eastern and southeastern regions show a significantly increasing trend. During this period, the rainfall has been mainly due to the passage of low pressure systems, depressions and cyclones near and over the country.

Figure $3(\mathrm{~d})$ shows rainfall trends during the Northeast Monsoon season (DecemberFebruary). Except for some very insignificant regions in the north and the south, the whole country shows an increasing rainfall trend during this season. The eastern and the northcentral parts have very significant upward trends. Usually, rainfall occurs in the northern and eastern regions during this season which is the dry season for the south-western and southern coastal areas and also for the central highlands. This observation suggests that the dry weather usually subdued.

\subsection{Variation of Rainfall Trends with the Traditional Climatic Zones}

Based on the climate of the country, Sri Lanka has been divided into three zones, namely WetZone, Intermediate Zone and Dry Zone and these are shown in Figure 4(a). This zonation is mainly based on the annual rainfall. The Wet Zone has an annual rainfall greater than $2500 \mathrm{~mm}$. The annual rainfall in the Intermediate Zone is between $2500 \mathrm{~mm}$ and $1750 \mathrm{~mm}$, and the Dry Zone has an annual rainfall less than $1750 \mathrm{~mm}$. 


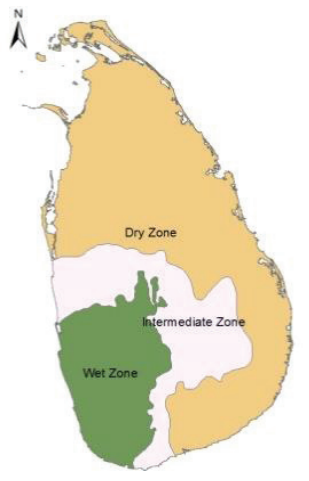

(a) Climatic zones

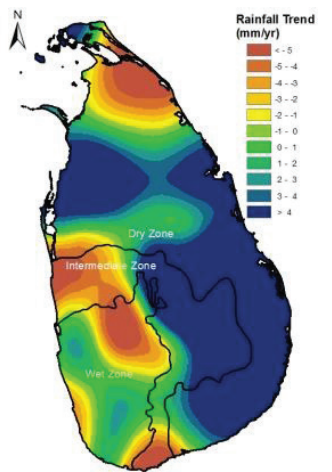

(b) Rainfall trends in different climatic zones
Figure 4 - Climatological zones and rainfall trends in the zones

As presented in Figure 4(b), a considerable part of the wet zone has had a decreasing rainfall trend over the last 50 years. The western slopes of the central highlands have had a significant decrease of rainfall trend compared to the other parts of the Wet Zone. Coastal regions of the Intermediate Zone have had a decreasing trend of rainfall while the eastern slopes of the central highlands have had an increasing trend. Most parts of the Dry Zone have had an increasing trend of rainfall. However, the northern region has had a decreasing trend of rainfall. This indicates that the rainfalls in these zones have changed over the last 50 year period.

\section{Conclusions}

In the present study, the analysis of rainfall trends in Sri Lanka over the period 50 year from 1966 to 2015 was done on an annual and seasonal scale at 32 rain gauging stations located around the country, using MannKendall Test and Sen's Slope estimator.

On the annual scale, a significant increase in the rainfall was found at four stations, namely those at Anuradhapura, Batticaloa, Pottuvil and Mapakadawewa. The Pottuvil station out of them, showed the highest rate of $19.89 \mathrm{~mm} / \mathrm{yr}$. Rainfall records at the stations at Chilaw, Dandeniya Tank and Iranamadu Tank showed a downward trend and among them the Dandeniya tank showed the highest decreasing trend of $8.734 \mathrm{~mm} / \mathrm{yr}$. The majority of the gauging stations had an upward trend. It is also clear that the eastern part of the country has had an increasing trend while the western region has had a decreasing trend over the period of analysis.

Rainfall has increased during the First-Inter Monsoon at most of the stations. However, the rainfall records of the Southwest Monsoon season indicate a downward trend in most parts of the country. It is noted that the SecondInter Monsoon period is characterized by an increase in the rainfall. Similarly, Northeast Monsoon season rainfall has also increased.

Usually, the Southwest Monsoon season and the Second-Inter Monsoon season are considered as wet seasons, both of which fall within the Maha season. Since the Southwest Monsoon has a decreasing rainfall trend, especially over the dry zone, the agricultural activities may get affected. The rainfall has gone up during the First-Inter Monsoon and Northeast Monsoon seasons, usually categorized as dry seasons.

The rainfall patterns in the three climatic zones have changed differently and thus the demarcation of these zones needs to be studied and amended appropriately. The study used rainfall data at 32 stations and therefore, the investigation of the trend with a higher number of gauging stations will be useful.

\section{References}

1. Jayawardene, H.K.W.I., Sonnadara, D.U.J. \& Jayewardene, D.R., Trends of Rainfall in Sri Lanka over the Last Century. Sri Lankan Journal of Physics, 6, 2005, pp.7-17.

2. Manawadu, L. \& Fernando, N., Climate Changes in Sri Lanka. Review Journal of the University of Colombo, Vol.01. No.2, 2008.

3. Malmgren, B.A., Hulugalla, R., Hayashi, Y. \& Mikami, T., Precipitation Trends in Sri Lanka since the 1870s and Relationships to El Ninosouthern oscillation. International Journal of Climatology, (23), 2003, pp.1235-52.

4. Nakagawa, K., Edagawa, H., Nandakumar, V. \& Aoki, M. (eds), Long-term Hydrometeorological Data in Sri Lanka, Special Research Project on Global Environmental Change. University of Tsukuba, Japan, 1995.

5. Turgay, P. \& Ercan, K., Trend Analysis in Turkish Precipitation Data. Hydrological Processes, 20, 2006, pp.2011-2026. 
6. Salmi, T., Detecting trends of annual values of atmospheric pollutants by the Mann-Kendall test and Sen's slope estimates -the excel template application MAKESENS. Helsinki, Finland: Finnish Meteorological Institute, 2002.

7. Mishra, A. K., Zger, M. O. \& Singh, V. P., Trend and Persistence of Precipitation under Climate Change Scenarios for Kansabati basin. India. HydrolProc, 23, 2009, pp.2345-2357.

8. Basistha, A., Arya, D. S. \& Goel, N. K., Analysis of Historical Changes in Rainfall in the Indian Himalayas, Int J Climatol. 29, 2009, pp.555-572.

9. Dufek, A. S., Ambrizzi, T., Precipitation Variability in São Paulo State, Brazil. TheorApplClimatol, 93 (3), 2008, pp.167-178.

10. Ya-ning, C., Wei-hong L., Chang-chun, X.U. \& Xin-ming, H.A.O., Effects of Climate Change on Water Resources in Tarim River Basin, Northwest China.J Environ Sci 19, 2007, pp.488493.

11. Sonali, P. \& Kumar, D. N., Review of Trend Detection Methods and their Application to Detect Temperature Changes in India.J. Hydrol. 476, 2013, pp. $212-227$.

12. Patra, J. P., Mishra, A. Singh, R. \& Raghuwanshi, N. S., Detecting Rainfall Trends in Twentieth Century (1871-2006) over Orissa State, India.Climate Change, Vol.111, 2012, pp.801-817. 